in tables 1-4 appears to be rather complex, they are well worth studying. The clinical setting is related to the likely flow rate required or, in the case of several examples in table 4, to the need for oxygen at all. This is turned into a practical approach to oxygen use in fig 1, which merits wall space in any emergency room, acute medical or respiratory unit. The second figure indicating how oxygen can be given in different environments is likely to be helpful to those less familiar with this practical but relevant skill.

Not only does this Guideline address practical aspects of oxygen delivery in many different settings but it also considers what information might be needed to set up or commission an oxygen service. One key recommendation is the use of an oxygen prescription chart which emphasises that oxygen really is a drug in a hospital setting, even if it does not need a formal prescription as when used in patient transfer. Paying attention to the flow rate of oxygen and how long it needs to be given to the patient will both improve patient safety and decrease inconvenience, for instance when oxygen is delivered for much longer than clinically indicated, hampering patient communication and increasing the worry of those relatives. The Guideline is supported by a wealth of appendices also available online which means that there is literally something here for everyone concerned with acute oxygen care.

The team who worked on this Guideline and especially Drs O'Driscoll,
Howard and Davidson, are to be congratulated on their hard work and commitment to deliver a comprehensive but ultimately practical guide as to how we should use one of our most familiar therapies. The challenge now falls to the rest of us to take the advice proffered, customise it to our own circumstances and ensure that the good sense contained with this Guideline translates into even better care for these acutely ill patients.

Competing interests: None.

Thorax 2008;63:849-850. doi:10.1136/thx.2008.105148

\section{REFERENCE}

1. O'Driscoll BR, Howard LS, Davison AG. BTS guideline for emergency oxygen use in adult patients. Thorax 2008;63;Suppl VI.

\title{
Recent advances in exacerbations of COPD
}

\section{Terence Seemungal, ${ }^{1}$ Annemarie Sykes, ${ }^{2}$ and the ICEAD Contributors}

The First International Conference on Exacerbations of Airways Disease (ICEAD) brought together experts from both sides of the Atlantic to discuss problems in the management of exacerbations of both asthma and chronic obstructive pulmonary disease (COPD). A brief overview of these discussions on COPD exacerbations follows.

\section{DEFINITIONS AND EPIDEMIOLOGY} Symptom and treatment based definitions Up to 18 definitions of a COPD exacerbation have been advanced, from less explicit ${ }^{1}$ to very explicit symptom based criteria. $^{23}$ However, large therapeutic trials in COPD have all used treatment based definitions. ${ }^{4}{ }^{5}$ The first consensus definition was treatment based but the current GOLD guidelines accept a symptom based definition. ${ }^{67}$ Biochemical or physiological markers applied in studies

\footnotetext{
${ }^{1}$ Department of Clinical Medical Sciences, University of West Indies, Mount Hope, Trinidad and Tobago;

${ }^{2}$ Department of Respiratory Medicine, National Heart and Lung Institute, MRC and Asthma UK Centre in Allergic Mechanisms of Asthma, Imperial College London, London, UK
}

Correspondence to: Dr Terence Seemungal, Department of Clinical Medical Sciences, University of the West Indies, St Augustine Campus, Trinidad and Tobago; tseemungal@aol.com using either definition ${ }^{89}$ have all shown significant changes, supporting the validity of these approaches to a definition but lack specificity and sensitivity. The healthcare utilisation approach to severity of exacerbation may be more robust as it has been related to mortality ${ }^{10}$ but does not allow for detection of untreated exacerbations, which may contribute to poor quality of life.

\section{Health burden}

COPD patients have about 0.5-3.5 exacerbations/year, 0.09-2.4 hospitalisations/year and inhospital mortality varies between $10 \%$ and $60 \%$, depending on the severity of COPD. Overall, the death rate varies from 5.4 per 1000 person years among normal subjects to 42.9 among subjects with GOLD stage 3 or $4 .{ }^{11}$ Thus COPD exacerbations are a significant cause of death, mainly in patients with more severe COPD. This leads to a high cost of COPD care which can be effectively reduced through decreasing hospitalisation. ${ }^{12}$

\section{AETIOLOGY AND SUSCEPTIBILITY Airway bacterial infection}

Bacteria may be detected in up to $60 \%$ of exacerbations and viruses in $23-60 \%{ }^{13}{ }^{14} \mathrm{~A}$ study of hospitalised patients found bacteria in $25 \%$, bacteria and viruses in $25 \%$ and viruses alone in 25\%, and no infectious agent in another $25 \% .{ }^{14}$ The acquisition of new strains of bacteria is associated with an increased risk of COPD exacerbation, more inflammation and strain specific immunity. ${ }^{1516}$ However, non-specific reduction of bacterial load during recovery from COPD exacerbation has been associated with resolution of inflammation. ${ }^{9}$

\section{Viruses and coinfection}

Respiratory viruses have been associated with higher exacerbation sputum interleukin (IL)-6 levels, with prolonged COPD exacerbations and significant health burden. ${ }^{3} 1718$ Furthermore, bacteria-virus coinfection leads to greater lung impairment and longer inhospital stay. ${ }^{14}$

\section{Susceptibility and inflammation}

Frequent COPD exacerbators appear to be a distinct phenotype characterised by a faster decline in lung function, poorer quality of life scores, more viruses at exacerbation, higher mortality, greater airway inflammation and higher airway bacterial load. ${ }^{3} 101319$ Frequent exacerbators also have smaller reductions in systemic inflammation post-exacerbation further. Interestingly, a high serum C reactive protein concentration post-exacerbation is associated with recurrence. ${ }^{20}$

\section{Susceptibility and other factors}

Viruses detected in lower airway samples of patients with stable COPD affect systemic inflammatory processes as well as lower airway bacterial load. ${ }^{13} 21$ Thus it is likely that the susceptibility of the frequent exacerbator phenotype is associated with viral colonisation of the lower airway though this has yet to be proved. 
Other factors that may affect susceptibility are upper airway inflammation and bacterial colonisation, previous infection with non-typeable Haemophilus influenzae, season and environmental temperature..$^{22} 23$

\section{PATHOGENESIS \\ Pathophysiology}

The acute and variable increase in end expiratory lung volume above its stable baseline is termed dynamic hyperinflation and occurs during COPD exacerbations. ${ }^{24}$ This leads to falls in spirometric parameters and increased functional residual capacity and residual volume. The resulting increased loading and functional weakness of the respiratory muscles may prevent a response to increased neural drive and thus neuromechanical uncoupling of the respiratory system occurs. This dissociation in response to acute dynamic hyperinflation is thought to contribute to the sensation of dyspnoea during COPD exacerbations. ${ }^{24}$

\section{Cell mediated mechanisms}

Both eosinophils and neutrophils are recruited during COPD exacerbations. ${ }^{14} 25$ Bacterial infection has been related to neutrophil chemoattractant gene expression which is upregulated during COPD exacerbation. ${ }^{1626}$

\section{Amplification of inflammation at COPD exacerbation}

The amplification of airway and mucosal inflammation at COPD exacerbation is thought to be due to activity along two pathways involving (a) nuclear factor $\kappa B$ (NFкB) translocation, which involves NFkB inducing kinase 2 (IKK2) and (b) mitogen activated protein kinase-p38 (p38-MAPK). ${ }^{27}$ These pathways are upregulated at COPD exacerbation ${ }^{28}$ and in the presence of non-typeable Haemophilus influenzae. ${ }^{27}$

\section{Oxidative stress at COPD exacerbation}

Compared with normal subjects, histone deacetylase (HDAC) activity is reduced in COPD and this reduction increases with increasing COPD severity and is associated with increased basal release of IL8 and tumour necrosis factor $\alpha$ (TNF $\alpha)$ that is poorly suppressed by dexamethasone thus indicating an association with steroid resistance in patients with $\mathrm{COPD}^{29}{ }^{30}$ Pro-oxidants are elevated during COPD exacerbation. ${ }^{31}$ Nitric oxide, for example, combines with superoxide anions to form peroxynitrite that in turn leads to nitration (and thus further inactivation) of HDAC2 and proteasome degradation, leading to amplification of the inflammatory cascade.

\section{EXPERIMENTAL TECHNIQUES AND CLINICAL TRIAL STRATEGIES \\ Experimental models}

Krug et al have advanced a lipopolysaccharide (LPS) challenge model of a COPD exacerbation that is safe with no significant effects on mean arterial pressure or heart rate. Using the model, instillation of LPS into a bronchopulmonary segment induces an inflammatory response similar to a COPD exacerbation. This model responds to treatment with anti-monocyte chemotactic protein 1 and to phosphodiesterase 4 inhibition. ${ }^{32} 33$

\section{Clinical trials}

A health care utilisation approach to staging is health system specific and affected by other features such as social support and patient affect as well as baseline health status and comorbidities which are not taken into account in the definition. Because of a variable recovery time which may depend on aetiology, the baseline of stability is difficult to determine for clinical studies. ${ }^{13}$

\section{Markers of COPD exacerbation}

Often, questionnaires have been designed by clinicians, and this has been found to lack primary validity by the Food and Drug Administration (FDA) in the USA. The FDA, however, is working with other bodies to develop a patient reported outcome tool to measure acute exacerbations. The patient identified attributes of exacerbations have been: cough, sputum, dyspnoea and chest discomfort, activity limitation, malaise, anxiety and sleep disturbance. It is believed that each of these attributes has a different time course. Unlike patient centred attributes, a biomarker is free from subjectivity but may be assay dependent.

\section{CURRENT AND FUTURE THERAPY How good is current therapy?}

Systemic steroids used at exacerbation lead to a faster recovery rate in lung function and symptoms, and are associated with a decreased relapse rate compared with placebo ${ }^{34} 35$ but are associated with hyperglycaemia, ${ }^{34}$ invasive aspergillosis and steroid psychosis. ${ }^{36} \mathrm{~A}$ meta-analysis of antibiotics for acute exacerbations of chronic bronchitis showed that secondline (newer) antibiotics are associated with greater "treatment success" and are not less safe when administered to patients at exacerbation than firstline agents. Systematic analyses show that antibiotics and systemic steroids decrease treatment failures within 30 days but only antibiotics improve mortality. ${ }^{38}$ Nevertheless, the mortality and hospitalisation rates following COPD exacerbations suggest that current treatment is still not optimal.

\section{Modifications of current therapy}

Long acting $\beta_{2}$ agonists may find increasing use as rescue therapy: formoterol and indacaterol as inhalers and arformoterol ( $\mathrm{R}$, R-formoterol) in nebulised form. Formoterol is being combined with several other inhaled steroids as has been done in asthma treatment. The long acting antimuscarinic, aclidinium, may also be useful as rescue therapy. Some anti-infective agents have importance in treating COPD exacerbations and these include antimicrobial peptides, new antiviral drugs which target unique viral genes and toll-like receptor antagonists.

Theophylline activates HDAC via a novel mechanism and restores HDAC activity in alveolar macrophages from patients with COPD. ${ }^{29}{ }^{39}$ Macrolides have anti-inflammatory activity and are effective in cystic fibrosis and diffuse panbronchiolitis. ${ }^{40}$ Both of these agents appear to potentiate the effects of steroids and thus different combinations of well known drugs may be more useful than current combinations.

\section{New anti-inflammatory drugs}

Phosphodiesterase inhibitors have been shown to inhibit the formation of reactive oxygen species and leukotriene B4 synthesis in vitro. ${ }^{41}$ Because of their systemic side effects, their use may require inhaled administration. Blockade of the NFKB pathway by an IKK2 inhibitor is associated with decreased granulocyte macrophage colony stimulating factor production and inhibition of p38-MAPK decreases luciferase activity in response to $\mathrm{TNF} \alpha /$ nontypeable Haemophilus influenzae. ${ }^{27}{ }^{42}$ Leukotriene B4 and IL8 antagonists have been shown to inhibit neutrophil chemotaxis, ${ }^{43}$ and combined blockade of the neutrophil chemokine receptors CXCR1 and CXCR2 slows LPS induced neutrophil migration. Most of these newer agents have yet to be tested in clinical trials.

\section{Future directions}

A definition based on prolonged deterioration in chronic symptoms is useful but subjective. A surrogate marker of a COPD exacerbation would be of interest but such a marker should have reproducibility, 
sensitivity to change and the clinically minimally important change in the marker must be known. Reducing hospitalisation rates through strategies to prevent COPD exacerbations may reduce the high health burden in COPD.

Further work must be done on the interaction between viruses and bacteria: does viral infection trigger the shift in strain of colonising bacteria seen during COPD exacerbations or is the effect mainly on bacterial load? Viruses are related to increased dyspnoea at exacerbation and thus an infective agent may be related to dynamic hyperinflation and hence to exacerbation severity. Frequent exacerbations are a marker of host susceptibility to exacerbation. Both prooxidants and chemokines cause inflammation through pathways mediated by NFкB. Blockade of steps along this pathway may be useful in attenuating the inflammatory response to infection. In the future, we may have to treat COPD exacerbations using receptor specific inhibitors along the inflammatory pathway.

Acknowledgements: Based on presentations at the first International Congress on Exacerbations of Airway Disease (ICEAD) Puerto Rico, 4-7 October 2007.

Competing interests: None.

- A list of the International Congress on Exacerbations of Airway Disease (ICEAD) contributors is published online only at http://thorax.bmj.com/content/vol63/issue10

Thorax 2008;63:850-852. doi:10.1136/thx.2008.099127

\section{REFERENCES}

1. Stark JE, Heath RB, Curwen MP. Infection with influenza and parainfluenza viruses in chronic bronchitis. Thorax 1965;20:124-7.

2. McHardy VU, Inglis JM, Calder MA, et al. A study of infective and other factors in exacerbations of chronic bronchitis. Br J Dis Chest 1980;74:228-38.

3. Seemungal T, Donaldson GC, Paul EA, et al. Effect of exacerbation on quality of life in patients with chronic obstructive pulmonary disease. Am J Respir Crit Care Med 1998:157:1418-22.

4. Burge PS, Calverley PMA, Jones PW, et al Randomised, double blind, placebo controlled study of fluticasone propionate in patients with moderate to severe chronic obstructive pulmonary disease: the ISOLDE trial. BMJ 2000;320:1297-303.

5. Wedzicha JA, Calverley PMA, Seemungal TAR, et al. The prevention of COPD exacerbations by salmeterol/ fluticasone propionate or tiotropium bromide. Am J Respir Crit Care Med 2007;177:19-26.

6. Rodriguez-Roisin R. Toward a consensus definition for COPD exacerbations. Chest 2000;117/Suppl 2):398S-401

7. Global Initiative for Chronic Obstructive Lung Disease. Global Strategy for the Diagnosis, Management, and Prevention of COPD. Summary of GOLD recommendations, with citations from the scientific literature. Revised 2006. http://www.goldcopd.com/ Guidelineitem.asp?|1 = 2 \&l2 = 1 \&intld = 996 (accessed 7 July 2008).

8. Bhowmik A, Seemungal TAR, Sapsford RJ, et al. Relation of sputum inflammatory markers to symptoms and lung function changes in COPD exacerbations. Thorax 2000;55:114-20.

9. White AJ, Gompertz S, Bayley DL, et al. Resolution of bronchial inflammation is related to bacterial eradication following treatment of exacerbations of chronic bronchitis. Thorax 2003;58:680-5.

10. Soler-Cataluña JJ, Martínez-García MAMÁ, Román Sánchez P, et al. Severe acute exacerbations and mortality in patients with chronic obstructive pulmonary disease. Thorax 2005;60:925-31.

11. Mannino DM, Doherty DE, Sonia Buist A. Global Initiative on Obstructive Lung Disease (GOLD) classification of lung disease and mortality: findings from the Atherosclerosis Risk in Communities (ARIC) study. Respir Med 2006;100:115-22.

12. Nurmagambetov T, Atherly A, Williams $\mathrm{S}$, et al. What is the cost to employers of direct medical care for chronic obstructive pulmonary disease? COPD 2006;3:203-9.

13. Seemungal TAR, Harper-Owen R, Bhowmik A, et al. Respiratory viruses and symptoms, inflammatory markers in acute exacerbations of COPD. Am J Respir Crit Care Med 2001:164:1618-23.

14. Papi A, Bellettato CM, Braccioni F, et al. Infections and airway inflammation in chronic obstructive pulmonary disease severe exacerbations. Am J Respir Crit Care Med 2006:173:1114-21.

15. Sethi S, Evans N, Grant BJ, et al. New strains of bacteria and exacerbations of chronic obstructive pulmonary disease. N Engl J Med 2002;347:465-71.

16. Chin CL, Manzel LJ, Lehman EE, et al. Haemophilus influenzae from patients with chronic obstructive pulmonary disease exacerbation induce more inflammation than colonizers. Am J Respir Crit Care Med 2005;172:85-91.

17. Seemungal TAR, Harper-Owen R, Bhowmik A, et al. Detection of rhinovirus in induced sputum at exacerbation of chronic obstructive pulmonary disease. Eur Respir J 2000;16:677-83.

18. Falsey AR, Hennessey PA, Formica MA, et al. Respiratory syncytial virus infection in elderly and high-risk adults. N Engl J Med 2005;352:1749-59.

19. Donaldson GC, Seemungal TAR, Bhowmik A et al. Relationship between exacerbation frequency and lung function decline in chronic obstructive pulmonary disease. Thorax 2002;57:847-52.

20. Perera WR, Hurst JR, Wilkinson TMA, et al. Inflammatory changes, recovery and recurrence at COPD exacerbation. Eur Respir J 2007;29:527-34.

21. Wilkinson TMA, Donaldson GC, Johnston SL, et al. Respiratory syncytial virus, airway inflammation, and FEV1 decline in patients with chronic obstructive pulmonary disease. Am J Respir Crit Care Med 2006;173:871-6.

22. Hurst JR, Perera WR, Wilkinson TMA, et al. Systemic and upper and lower airway inflammation at exacerbation of chronic obstructive pulmonary disease. Am J Respir Crit Care Med 2006;173:71-8.

23. Abe Y, Murphy TF, Sethi S, et al. Lymphocyte proliferative response to $\mathrm{P} 6$ of Haemophilus influenzae is associated with relative protection from exacerbations of chronic obstructive pulmonary disease. Am J Respir Crit Care Med 2002:165:967-71.

24. O'Donnell DE, Parker CM. COPD exacerbations 3: Pathophysiology. Thorax 2006;61:354-61.

25. Saetta M, Turato G, Maestrelli $P$, et al. Cellular and structural bases of chronic obstructive pulmonary disease. Am J Respir Crit Care Med 2001;163:1304-9.

26. Oiu Y, Zhu J, Bandi V, et al. Biopsy neutrophilia, neutrophil chemokine and receptor gene expression in severe exacerbations of chronic obstructive pulmonary disease. Am J Respir Crit Care Med 2003;168:968-75

27. Watanabe T, Jono $\mathrm{H}$, Han J, et al. Synergistic activation of NF- $\kappa \mathrm{B}$ by nontypeable Haemophilus influenzae and tumor necrosis factor-alpha. PNAS 2004;101:3563-8.

28. Caramori G, Romagnoli $\mathrm{M}$, Casolari $\mathrm{P}$, et al. Nuclear localisation of p65 in sputum macrophages but not in sputum neutrophils during COPD exacerbations. Thorax 2003:58:348-51.

29. Cosio BG, Tsaprouni L, Ito K, et al. Theophylline restores histone deacetylase activity and steroid responses in COPD macrophages. J Exp Med 2004;200:689-95

30. Ito K, Ito M, Elliott WM, et al. Decreased histone deacetylase activity in chronic obstructive pulmonary disease. N Engl J Med 2005;352:1967-76.

31. Maziak W, Loukides S, Culpitt S, et al. Exhaled nitric oxide in chronic obstructive pulmonary disease. Am J Respir Crit Care Med 1998:157:998-1002.

32. Hohlfeld JM, Schoenfeld K, Lavae-Mokhtari M, et al Roflumilast attenuates pulmonary inflammation upon segmental endotoxin challenge in healthy subjects: A randomized placebo-controlled trial. Pulm Pharmacol Ther 2008 Feb 21 (Epub ahead of print).

33. Krug N, Larbig M, Bonner J, et al. Anti-MCP-1 monoclonal antibody (ABN912) attenuates LPSinduced monocyte recruitment into the lung in patients with COPD. Proc Am Thorac Soc 2006:3:A849.

34. Niewoehner DE, Erbland ML, Deupree RH, et al Effect of systemic glucocorticoids on exacerbations of chronic obstructive pulmonary disease. Department of Veterans Affairs Cooperative Study Group. N Engl J Med 1999:340:1941-7.

35. Aaron SD, Vandemheen $\mathrm{KL}$, Hebert $\mathrm{P}$, et al Outpatient oral prednisone after emergency treatment of chronic obstructive pulmonary disease. N Engl J Med 2003;348: 2618-25.

36. Dimopoulos G, Piagnerelli M, Berre J, et al. Disseminated aspergillosis in intensive care unit patients: an autopsy study. J Chemother 2003;15:71-5

37. Ram FSF, Rodriguez-Roisin R, Granados-Navarette A et al. Antibiotics for exacerbations of chronic obstructive pulmonary disease. Cochrane Database Syst Rev 2006;CD004403

38. Wood-Baker RR, Gibson PG, Hannay M, et al. Systemic corticosteroids for acute exacerbations of chronic obstructive pulmonary disease. Cochrane Database Syst Rev 2005;1:CD001288.pub2.

39. Ito K, Lim S, Caramori G, et al. A molecular mechanism of action of theophylline: induction of histone deacetylase activity to decrease inflammatory gene expression. Proc Natl Acad Sci U S A 2002;99:8921-6.

40. Saiman L, Marshall BC, Mayer-Hamblett N, et al. Azithromycin in patients with cystic fibrosis chronically infected with Pseudomonas aeruginosa: a randomized controlled trial. JAMA 2003;290:1749-56.

41. Hatzelmann A, Schudt C. Anti-inflammatory and immunomodulatory potential of the novel PDE4 inhibitor roflumilast in vitro. J Pharmacol Exp Ther 2001;297:267-79.

42. Smith SJ, Fenwick PS, Nicholson AG, et al. Inhibitory effect of p38 mitogen-activated protein kinase inhibitors on cytokine release from human macrophages. Br J Pharmacol 2006;149:393-404.

43. Beeh KM, Kornmann 0, Buhl R, et al. Neutrophil chemotactic activity of sputum from patients with COPD: role of interleukin-8 and leukotriene B4. Chest 2003; 123:1240-7. 